\title{
The Role of Foreign Language Learners' Self- Esteem in Enhancing Their Oral Performance
}

\begin{abstract}
:
Nowadays, the affective side of learners receives a noticeable attention in the learning process, mainly personality factors. The present study aims to explore the relationship between Algerian second year LMD Students of English as foreign language' self-esteem level and their oral production at the University of Constantine 1, Algeria. The hypothesis states that the more Algerian second year students of English, at the University of Constantine 1, trust their abilities, the more they will be able to enhance their English speaking performance. The research work is mainly concerned with finding whereby the feeling of "I am able to do it" has any relation with learners' oral production. The research methodology adopted in this study is a descriptive one. It intends to describe two variables: selfesteem as the supposed independent variable and foreign language speaking as the assumed dependent variable, and to identify the relationship between them. Data were gathered through a series of questionnaires administered to a random sample of 30 Algerian second year LMD students and delivered to 10 teachers of Oral Expression, both at the English Department, University of Constantine 1. The results obtained from the present research show that there is a positive relationship between students' self-esteem and their foreign language speaking performance, and that this relationship affects directly their level of academic achievement, in general. Furthermore, on the light of this study, it is possible to put forward that a learner is his /her real judge in learning a foreign spoken language. Overall, the results obtained lead us to suggest that learners must pay more attention to their self-esteem for better oral performance.
\end{abstract}

Key Words: Affective factors, self-esteem, foreign language speaking skill.

\section{BOUCHAREB Naouel}

Faculty of Letters and Languages

Department of Foreign Languages

University of Mentouri

Constantine

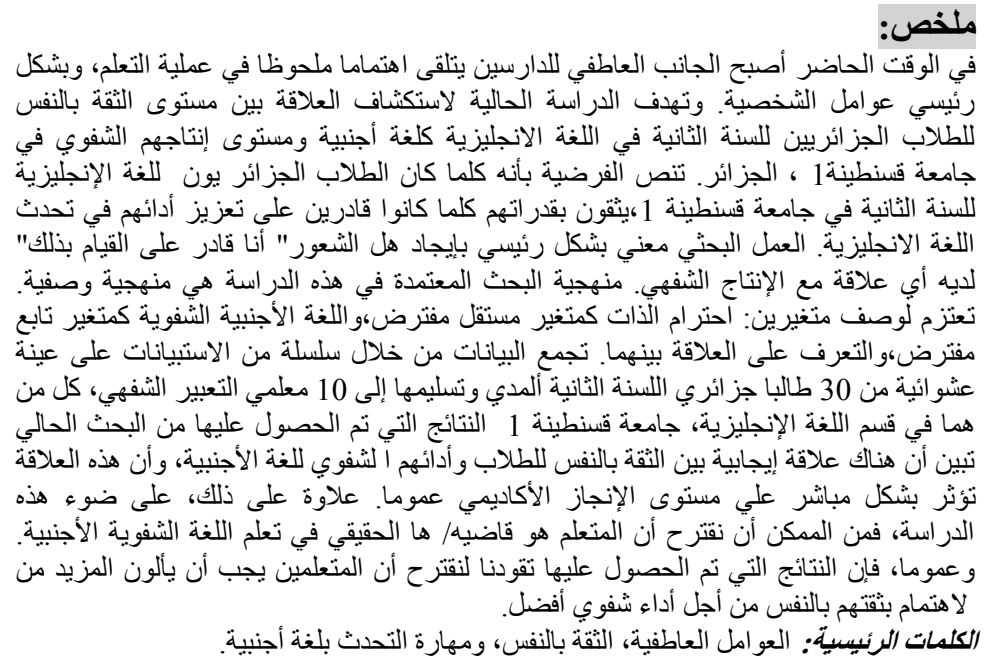

\section{Introduction:}

In a foreign language teaching class, today's professional interest is on the students' speaking skill development, because, in general, success is shown through the speaking ability, as mentioned by Nunan (1991: 39)

"To most people, mastering the art of speaking is the single most important factor of learning a second or 
foreign language, and success is measured in terms of the ability to carry out a conversation in the language".

Thus, speaking is a crucial skill in learning a foreign language. It is very important to experience real communicative situations in which learners will learn how to express their own views and opinions and to develop their oral fluency and accuracy which are very essential for the success of second language communication.

Speaking, in particular, is one of the four skills, (namely, listening, writing, and reading) which requires special abilities to be mastered, as it is an exchangeable affection between the teacher and the learner. For that reason, a greater opportunity of the psychological principles is being truly demanded in learning to speak. Human affective factors are essential for human language acquisition. Therefore it is necessary to understand the general nature of human learning such as learning and training. The training of students requires a special deep psychological knowledge on the part of the teacher as well as on the part of the learner, too.

Language acquisition cannot take place without affect according to many studies, as the one of Rodríguez, Plax and Kearney (1996: 297) who has explained that, "Affect is by definition, an intrinsic motivator. Positive affect sustains involvement and deepens interest in the subject matter". So, nowadays, the truth about affect presence in realizing success in language acquisition is a must because successful language learning depends lot on these factors.

Most foreign language teachers agree that the most powerful factor in language learning is learner's psychological factor, as mentioned by one of Stevick's candidate (1980: 4) about how success in this process depends less on materials, techniques and linguistic analysis and more on what goes on inside and between the people in the classroom".

Again, the majority of foreign language teachers may agree that selfesteem is the foremost needed for effective learning to take place. It is common to think that if we trust our own capacities, we will learn to speak easily. Noticeably, students who have a high level of self-esteem find it enjoyable to learn how to talk, whereas students with a low self-esteem are not motivated to speak, they feel afraid and inhibited when they come to share their opinions orally with others. As a result, they often lose marks concerning their academic level in speaking. Thus, teachers are required to make lot of efforts to find how to foster learners' self-esteem for effective speaking, and most importantly draw their students' attention to the relative significance of having faith in their beliefs about their capacities, in order to achieve better outcomes in speaking the foreign language, and teach them that self-esteem has the total power to positively direct their results in speaking. 


\section{Introducing the Key Terms of the Present Study}

\subsection{The Speaking Skill}

According to Bygate (1987), the speaking skill demands special care like the other skills, for both the mother tongue and the foreign language, as it requires a firm trust on one' s own abilities to reach goals that are aimed at. It is the skill whereby others recognize us through what we say and how we think as well. As it is the skill whereby people befriend or separate others. Since it is the means of expressing and moving the solidarity of societies, social positions, it is an excellent tool for allowing the learning of languages to take place. Clark and Clark (1977) have argued that speakers who speak in order to influence their listeners, through asking questions to get information, use speaking as a tool and, also, they engage in many activities to reach their goals.

\subsection{Affective Domain}

First, it is worth defining the affective domain as a general term that covers all the affective variables. It is important to mention that the affective side is not a widespread mentioned concept, because it is concerned with emotions, feelings, and affection, in general as stated by Bloom and his colleagues (Krathwohl, Masia, 1964). However, in these recent years the importance of affect in learning has turned to be a questionable topic and many academic researchers have done lot of work to investigate its importance; which leads them, through research, to make sure that some affective factors influence EFL/ESL learning to a great extent. Defining the affective variables is elusive; thus, an overview of the ones considered to be influenced by the teacher's attitude will be briefly described below. About the definition of affect, Brown (2000: 143) has posited that: "the affective domain is the emotional side of human behaviors and it may be juxtaposed to cognitive side", likewise, Oxford (1990) has viewed affect as emotions, attitudes values, and motivation. Gardner and Mac (1992: 3) also have argued that affective variable, are those "emotionally relevant characteristics of the individual that influence how he/she will respond to any situation". Therefore, we deduce that the affective side of the learner contributes to at least as much and often more to language learning (Stern 1983).

\subsection{Self-Esteem}

Self-esteem is one of the affective factors that influence human's production among many others; Brown (2007: 154) has posited that:

"Self-esteem is probably the most pervasive aspect of human behaviour. It could easily be claimed that no successful cognitive or affective activity can be carried out without some degree of self-esteem, self-confidence, knowledge of yourself and self-efficacy belief in your own capacities to successfully perform that activity". 


\subsubsection{Levels of Self- Esteem}

According to Brown (2007), three levels of self-esteem have been described in the literature to capture its multi dimensions, namely, global, situational and task self-esteem.

\subsection{1. a. Global Self- Esteem}

It is a quite fixed and steady characteristic in grown up people, it does not change over time except through wide treatment. It is considered as the examiner of one's' own value across both time and discriminate situations.

\subsection{1. b. Situational Self- Esteem}

It refers to one's judgment of the value in his life as social interaction, work, education, home, or any certain relatively discretely defined traits such as intelligence, communicative ability, athletic ability, or personality traits like gregariousness, empathy, and flexibility to the circumstances and the particular qualities of personalities.

\subsection{1. c. Task Self- Esteem}

Task self-esteem is referred to it because it is connected to specific or particular tasks in particular circumstances. In scholar education, for example, task self-esteem is related to one side of subject-matter, or in athletic situations, a certain skill of sport is assessed in relation to task selfesteem.

All in all, self-esteem is proved through its levels and definitions that it has the most powerful impact on learners' results and it is in the learners' hands to be excellent or the reverse due to their feeling towards their capacities.

\subsubsection{Self- Esteem and Self-Efficacy}

One of the primary affective elements is self-efficacy. It is important, here, to understand the distinction between self-efficacy and self-esteem. Self-esteem is the person's feeling of his/her self-worth, whereas selfefficacy refers to the person's belief of his or her ability to reach a goal.

\section{Research Question}

At Constantine University, second year LMD learners of English are struggling to improve and develop their English communicative skills, in particular speaking. Although they have learned English for many years, the majority of them are still incapable of using English orally "they sometimes hesitate, repeat themselves, stutter or make slips of the tongue" Clark and Clark (1977: 6). Their poor achievement in oral productions is not always the consequence of any of the linguistic factors since many learners own the language competence and are being taught throughout effective processes' approaches, relates to psychological factors which are more concerned with the fear of making mistakes. 
This feeling comes from the low self-esteem they have. Someone with low self-esteem is believed to be unconfident, while confidence is strongly needed by learners to present their English orally. For Amato (2003), self-esteem is a very important factor in providing learners with the power to be motivated towards their own abilities to enjoy the learning process and experience real communication.

Gardner (1994) argued that students cannot defeat the fear that faces them in speaking the foreign language in the classroom. The problem we are confronted with in this research is the kind of relationship between learners' self-esteem and their speaking skills.

The precise questions we would ask are:

1 -What is the relationship between self-esteem and oral productions for $2^{\text {nd }}$ year LMD learners of English?

2-Do successful learners show higher self-esteem in oral tasks than do less successful learners?

\section{Hypothesis:}

This study will examine if self-esteem is helpful in oral production. If self-esteem can be proved to enhance learning, then one should pay due attention to his/ her self-esteem to heighten achievement in all subjects. Generally, foreign language students' failure to speak English in the classroom may emerge from at least two reasons:

One is that learners are really weak and they consider speaking in English a very difficult task; and the second one is that in spite of the students' knowledge, there are some personality factors like self-esteem which will prevent them from doing so if not raised. In other words, the general hypothesis can be stated as follows: if second LMD learners of English trust their own abilities or if they have faith in their abilities, they will be more motivated and energetic to become positive about their own oral skill production.

\section{Method}

\subsection{Subjects}

The actual problem was observed among all levels of students in English LMD classes at Constantine 1 University in Algeria. Because of the huge number, we decided to work only with 2 nd year level since throughout the first year, students were trained using all the teaching processes' approaches and were learning new language competence. Thus, in their second year, students are supposed to be able to take-risks in speaking since they have started to develop their self-esteem from their first year. Out of 20 groups constituting a population of one thousand and a hundred and sixty seven students (1167), we will select randomly one group of 30 students; the students in this class will be all of mixed ages and sexes (males and 
females). Males are about $20 \%$ and females are about $80 \%$ - but the variable sex is not considered in this research since the tools of the research used (questionnaires essentially) are not tests which will yield scores to evaluate objectivity, the levels and the attitudes allowing this between sex differences - being selected randomly. We assume that our sample of students would be homogeneous in terms of instructions input and cultural environment. As for teachers, we select randomly a sample of 12 teachers of oral expression module among 30 teachers; both samples were selected in Mai 2010.

\subsection{Tools of the Research}

In order to check our hypothesis, to obtain the information required from our subjects, and to fit the objectives of our present research, we will be using one main tool which is a questionnaire.

First, a formal questionnaire will be given to teachers to ensure that their responses and recommendations are the result of their long interaction with English language learners during many years of observation of learners' performance, particularly teachers of oral expression module. It is also about their opinions towards self-esteem as a significant criterion for effective language learners speaking production positively. Further, it seeks to probe their opinions about their focal point in teaching oral expression module, in addition to a small comparison of the presence of shyness in other skills and its relation to oral expression module, their opinions about the reasons of students' failure in speaking.

The second questionnaire will be directed to 2nd year English students at the University of Constantine 01 to know their points of view about selfesteem and oral performance, in general. It was mainly about their own information about their level, to know about their self-esteem, then about their perception of the easiness or difficulty of the speaking skill. We also asked them about their views concerning the reasons which either motivate or cause failure to talk in the classroom, the effects of shyness on their selfesteem pertaining to the skill of speaking and the effects of their positive thinking on their level of interaction in the classroom.

If the information obtained through the use of a questionnaire can be of value, it is nevertheless not enough. To consolidate, for more objectivity, we do believe that the inclusion of another data gathering tool would be indispensable. The administration of a test would be of great importance for our investigation by testing the attitudes and the reactions of our sample of students towards the role of self-esteem in enhancing their oral performance. This would show effectively whether the results obtained are or not in the direction of our hypothesis and would reinforce the probability of getting positive results, however because of the constraints of time, the test was prepared, but we could not find the time to do it. Hence, we believe 
that questionnaires would be of great value if they are well-structured and adequately interpreted, and consequently there analyses will cast some light on the importance of self-esteem for better English language speaking in the language classroom.

\section{Results and Discussion}

The results of the teachers/students' questionnaire are presented, here. Some of the responses are significant in terms of the positive attitudes they displayed towards effective speaking through self-confidence, while some others are not.

As a result, our research findings (the analysis of the questionnaires) display considerable agreements with what we have set before as an assumptions and supposition, that indeed the that, indeed, feeling of self-esteem boosts learners' oral performance.

\subsection{Teachers' Questionnaire}

Basically out of (120) questions, (110) answers indicate interestingly that teachers are supporting greatly our assumptions with regard to the teaching and learning situation:

- $100 \%$ of the total respondents $(\mathrm{N}=10)$ said that they consider self-esteem as an important aspect of successful speaking, this is indeed in the direction of our hypothesis, and shows that all the teachers are aware and conscious of the role of self-confidence in learners' spoken language.

$-30 \%$ of the total respondents said that they always try to show to their learners the importance of believing in their abilities in order to speak successfully, while $40 \%$ said they often do that, and $20 \%$ said they sometimes do, against $10 \%$ who said that they rarely draw their learners' attention to the importance of self-esteem for better results. All in all, about $70 \%$ agree that learners must believe in their abilities, which proves that self-esteem as an underlying factor is important for better speaking. This again indicates the importance teachers give to this affective factor which is in accordance with our hypothesis.

$-70 \%$ said that they teach learners that they are as they mirror themselves, and $30 \%$ said that they do not teach their students so. That shows that teachers think that if students believe they are good speakers and they are well articulators, they will be good speakers in reality, if not this image will be reflected negatively in their real academic life. This is another support for our assumption.

- In fact, $20 \%$ said that they focus on learners' affective and attitudinal factors, $20 \%$ said they focus on the appropriate and effective teaching methodology. $10 \%$ meanwhile, said they focus on the necessary teaching environment, while $50 \%$ said they focus on all of them. In this question, teachers' answers were not really in the direction of our hypothesis because 
their answers were concentrating on all the suggestions mentioned in this question not only the affective factors' suggestion.

- $100 \%$ agree that there are students who get good marks in grammar and phonetics but do not do as well in oral expression. This question was to show that rather than linguistic and teaching methodology, there exist other reasons that influence the learners' learning a foreign language, which is in our case self-esteem.

- A frank question was directly asked to teachers about the reason behind students' failure in the speaking production, with another choice. The answer was clear cut that self-esteem has the most powerful influences on students' level in speaking English. In terms of percentage, 20\% said that students' failure is due to the fact that speaking is a difficult task for them; against $80 \%$ who stated that their failure refers to the low self-esteem they have.

\subsection{Students' Questionnaire}

About learners' questionnaire, and as a global analysis of students answers, we can understand, with some relief, that approximately out of (363) questions, (350) students' answers show that they are more or confident in their abilities to learn English i.e. having a high level of selfesteem. They are also supporting our prediction concerning the significance of the feeling of self-esteem to enhance their oral performance.

$-20 \%$ of students said that failure is due to the fact that speaking is a difficult task, against $80 \%$ who stated that their failure refers to the low self-esteem they feel. This way of thinking is supporting the assumption that self-esteem is the director for speaking positively.

- $66.66 \%$ of students said that they try speaking in the classroom, because they feel they can speak English, and $26.67 \%$ admitted that they participate orally just because they are afraid about the mark. Here, this question is very important because it shows us the power of self-esteem in pushing learners to talk in comparison with another weak factor which is the fear about the mark which imposes itself as the only way to succeed and often the essential aim of learners. Thus, self-esteem is really a crucial element for communications and, thus, for marks.

- To confirm or disconfirm our hypothesis, the following question was about shyness which results from low self-esteem. $46.66 \%$ said that they do not keep silent when they feel they need to speak with their friends. $53.33 \%$ agree that they really keep silent with their friends. So, the answers showed that shyness is a barrier to talk with friends.

- Concerning shyness as an obstacle to speaking for students, this question was directed to have answers which are although not with a significant difference but still with a clear proportion of difference that learners' shyness is a real barrier for the spoken language to take place. The results 
were that $46.66 \%$ of learners said they keep silent for the reason of being shy to speak with native speakers, while $43.33 \%$ of them do not keep silent when they feel shy speaking to native speakers.

- $40 \%$ said that the reason behind their silence were difficulties in speaking English, whereas; $60 \%$ of them answered that they feel shy to speak to their teachers, which does not allow them to practice their oral English. This question is just like the all abovementioned questions which turn around the fact that self-esteem is the powerful factor among many other factors to influence speaking. The answers to this last question are, in general, in the direction of our hypotheses. Shyness is the lack of confidence which brings low self-esteem that keeps students silent because of the fear of making mistakes.

\section{Conclusion}

The present study has covered the problem of how self-esteem affects learners' level of oral expression achievement. It was mainly interested in checking the fact that learners of English, who trusted their own abilities, would be more energetic and motivated to become positive about their own oral skill productions. Through analyzing the impact of high self-esteem on learners' oral achievements and, therefore, on their success in general, our research finding sheds some light on its significance to markedly account for spoken language learners' academic achievements. The results that we have obtained are in the direction of our research hypothesis, that students of lower self-esteem have a low level of spoken language achievement, despite the fact that they have real linguistic abilities, while students of higher self-esteem attain a good level of spoken language production. We, also, ensure the idea that foreign language learners' beliefs affect their selfdecision on their spoken language performance. Self-esteem is one of the affective factors that cannot be neglected for its considerable help. Likewise, Brodkey and Shore (1976) claim that Self-esteem is an effective factor in learning the oral skill of a foreign language. For that reason, we must notice that besides teaching the linguistic competence to learners, there must pay a due attention must be paid to learners' affective domains, in particular their self-esteem to increase their academic level in oral performance positively. Therefore, we end this article by some very general suggestions, that, we hope, will help teachers in the foreign oral language classroom, and notably, for learners, to trust their abilities and give importance to themselves in peaking the foreign language, far from fear and shyness, and for teachers to pay significant attention to the affective domains influencing second/ foreign language learners. 


\section{Bibliography}

Amato, R. P. (2003). Making it Happen. From Interactive to Participatory. (3rd ED).White Plains NY: Pearson Education. Bloom, B., Krathhol, D., and Masia, B.(1964). Taxonomy of Educational Objectives. Handbook H: Affective Domain. New York: David Mckay Brodkey, D., \& Shore,H.(1976).Students' personality and success in an English languageprogram. Language Learning . 26. 153-162. University of Michigan.

Brown, H. D. (2000).). Principles of language learning \& teaching. (4th Ed.). New York: Longman.

Brown, H.D. (2007). Principles of Language Learning and Teaching. (4th ED) PearsonEducation LTD.

Bygate, M. (1987). Speaking. Oxford: Oxford University Press.

Clark, H. H., \&Clark, E.V. (1977).Psychology and Language. An introduction topsycholinguistics. New York: Harcourt Brace Javanovich.

Gardner, R. c, (1994). The Subtle Effects of Language Anxiety on Cognitive Processing in Second Language. Language Learning .London: Longman.

Gardner , R. C. and MacIntyre, P. D.( 1993). A Student's Contributions to Second language Learning . Part II : Affective variables . Language Teaching 26,1- 11 .

Luoma, S. (2009). Assessing speaking. (J. C. Alderson, \& L. F. Bachman, Ed.) Cambridge university press.

Nunan,D.(1991).Language teaching methodology .A textbook for teachers. New York,Pentice Hall Intermediate (UK)LTD.

Oxford, R. (1990). Language learning strategies, what every teacher should know. U.S.A: Heilene \& Heilene Publishers.

Rodríguez, J.I., Plax, T.G., \& Kearney, P.(1996). Clarifying the relationship between teacher nonverbal immediacy and student cognitive learning: Affective learning as the central causal mediator. CommunicationEducation, 45 , 293-305

Stern, H.H. (1983). Fundamental Concepts of Language Teaching. Oxford: Oxford

University Press.

Stevick, E.W. (1980). Teaching Languages: a Way and Ways. Rowley, M.A.: Newbury House. 